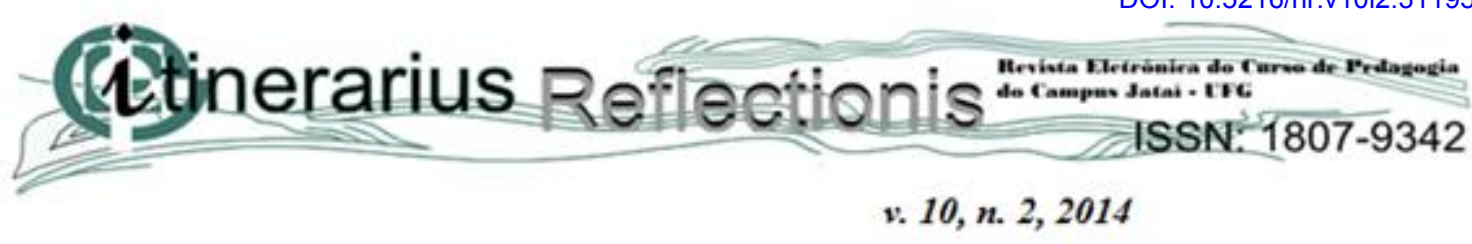

\title{
REVISITANDO A TEORIA ATRIBUCIONAL: COMPREENDENDO AS RELAÇÕES INTERPESSOAIS EM SALA DE AULA
}

\author{
Mirella Lopez Martini Fernandes Paiva \\ Psicóloga, Mestre em Educação \\ (Psicologia Educacional - UNICAMP) \\ Doutora em Ciências (Psicologia - USP). \\ mirellapaiva@gmail.com
}

Evely Boruchovitch

psicóloga, $\mathrm{PhD}$ em Educação pela University of Southern California, Los Angeles, professora Livre-Docente do Departamento de Psicologia Educacional da Faculdade de

Educação da Universidade de Campinas, membro do GEPESP - UNICAMP. evely@unicamp.br

Resumo: A Teoria Atribucional de Weiner é muito importante para a compreensão das relações entre pensamentos, sentimentos e ação em contexto escolar. As atribuições de causalidade são crenças sobre as causas responsáveis por experiências de sucesso e fracasso. Embora no início essa abordagem tenha se concentrado nos estudos sobre como indivíduos interpretam suas próprias experiências de sucesso e fracasso escolar (foco intrapessoal), ela se mostrou relevante também na perspectiva interpessoal, ou seja, na compreensão de fenômenos importantes que ocorrem em contexto social e escolar, tais como: reações a estigmas ou rótulos, agressão, altruísmo, comportamento de ajuda, punição, entre outros. Revisitar a Teoria Atribucional nas perspectivas intra e interpessoal e analisar como as crenças atribucionais de professores e alunos podem afetar a qualidade das relações interpessoais em sala de aula, o desempenho acadêmico e a prática docente foram os objetivos deste artigo.

Palavras-Chave: atribuições de causalidade; desempenho acadêmico; interações no contexto escolar.

\section{REVISITING ATTRIBUTIONAL THEORY: UNDERSTANDING INTERPERSONAL RELATIONS IN THE CLASSROOM}

Abstract: Weiner's causal attribution theory is very important to understand the relationship between thoughts, feelings and action in the school context. Causal attributions are beliefs about the causes of experiences of success and failure. Although at the beginning this approach has focused on studies of how people interpret their own experiences of success and 


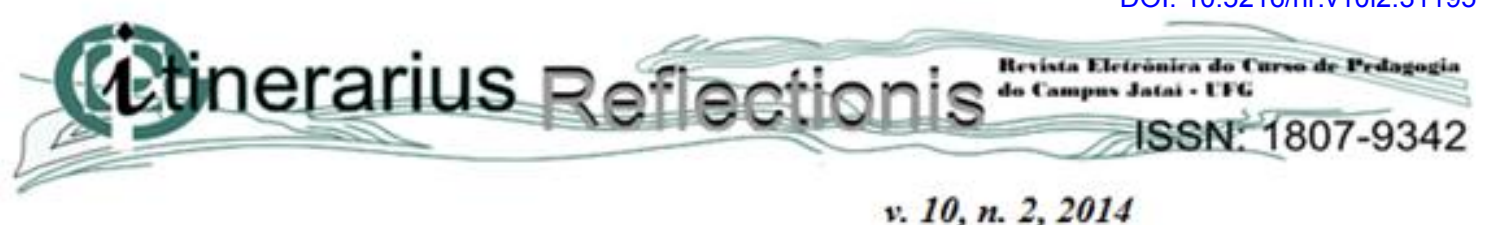

v. 10, n. 2,2014

failure in school (intrapersonal focus), Causal Attribution Theory turned out to be relevant also for understanding important phenomena which occur in social and school settings (interpersonal focus) such as reactions to stigmas or labels, aggression, altruism, helping behavior, punishment, among others. To Revisit the Attributional Theory on both intra and interpersonal perspectives and to analyze how teachers and students' attributional beliefs can affect the quality of interpersonal relationships in classroom, the academic performance and teaching practices were the purposes of this article.

Key-Words: causal attributions; school achievement; school interactions

Os estudos iniciais sobre ensino e aprendizagem partiram do pressuposto de que programas sistematizados de educação garantiriam a aprendizagem dos alunos, por meio da simples transmissão e recepção de conhecimentos pré-definidos. Essa concepção foi sendo gradualmente substituída por diversas abordagens que passaram a enfatizar o papel ativo dos professores e dos alunos na relação pedagógica. Em outras palavras, as cognições, afetos e comportamentos de professores e alunos passaram a ser vistas de forma mais orgânica e integrada à prática pedagógica e seus produtos (MIRANDA \& ALMEIDA, 2009; SACRISTÀN \& GOMES, 1998).

Nessa perspectiva, o papel do professor e de suas características vem sendo amplamente reconhecido como um dos principais fatores que influenciam a qualidade da relação pedagógica e da aprendizagem dos alunos na escola. Crenças, sentimentos, expectativas e habilidades de professores podem afetar e são afetadas pelas características das relações professor-aluno e, por essa via, influenciam o desenvolvimento, a aprendizagem e o desempenho dos alunos (BORUCHOVITCH, 1994; ROSENTHAL \& JACOBSON, 1968; PAIVA \& DEL PRETTE, 2009; PAJARES, 1992).

Embora a literatura internacional (BERRY, 2006; BRIGHTON, 2003; CALDERHEAD, 1996; ERRINGTON, 2004; WARFIELD, WOOD \& LEHMAN, 2005) venha nos últimos anos demonstrando o impacto e a relevância das variáveis cognitivas e afetivas sobre as ações dos professores em sala de aula e sobre a aprendizagem dos alunos, as pesquisas e reflexões sobre o tema no Brasil são ainda incipientes, justificando o investimento de esforços em se compreender e intervir sobre esse aspecto em nosso meio 


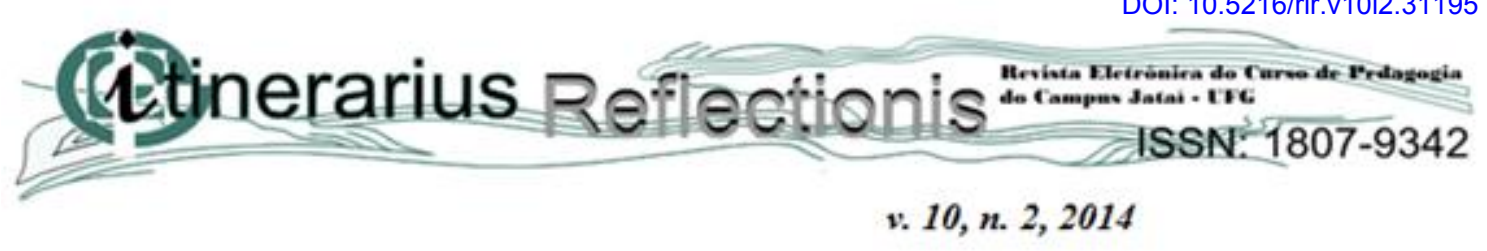

(BORUCHOVITCH, 1994; BORUCHOVITCH \& MARTINI, 1997; GANDA \& BORUCHOVITCH, 2011; PAIVA \& DEL PRETTE, 2009).

Um importante referencial teórico para análise e compreensão das relações entre pensamentos, sentimentos e ação em contexto escolar é a Teoria da Atribuição de Causalidade de Weiner (1985). As atribuições de causalidade dizem respeito às crenças pessoais sobre as causas responsáveis pelas experiências de sucesso e fracasso (WEINER, 1985). A pertinência e adequação de se compreender esses processos por meio das atribuições de causalidade vêm sendo cada vez mais reconhecida na literatura da área (ALMEIDA \& GUISANDE, 2010; BORUCHOVITCH \& MARTINI, 1997; MARTINI \& BORUCHOVITCH, 2004).

Pesquisas sobre o tema mostram que as atribuições dos professores para o desempenho acadêmico dos seus alunos, bem como as atribuições que os alunos fazem do seu próprio desempenho afetam as expectativas de sucesso e fracasso, o rendimento acadêmico, as emoções e a motivação desses alunos, bem como a qualidade das relações interpessoais estabelecidas em sala de aula (ALMEIDA \& GUISANDE, 2010; MARTINI \& BORUCHOVITCH, 2004; MARTINI \& BORUCHOVITCH, 2001; MIRANDA, ALMEIDA, BORUCHOVITCH, ALMEIDA \& ABREU, 2012). O objetivo deste artigo é revisitar a Teoria Atribucional de Weiner (2006) em sua perspectiva intra e interpessoal e, com base neste modelo e em seus resultados de pesquisa, analisar como as crenças atribucionais de professores e alunos podem afetar a qualidade das relações interpessoais em sala de aula, bem como o desempenho acadêmico e a prática docente.

A Teoria Atribucional de Weiner: um olhar sobre as perspectivas intra e inter e suas relações com o contexto escolar.

Há cerca de 40 anos a Teoria Atribucional se destaca como uma das concepções proeminentes nos estudos sobre motivação, na psicologia social e, também, na psicologia educacional, com um sólido embasamento teórico e empírico, revelando, ainda, alta consistência dos seus achados em diferentes culturas (WEINER, 2006; 2010). A premissa básica da Teoria Atribucional é de que as pessoas buscam compreender, prever, controlar e organizar seus eventos de vida e, para isso, desenvolvem um conjunto de pensamentos ou 


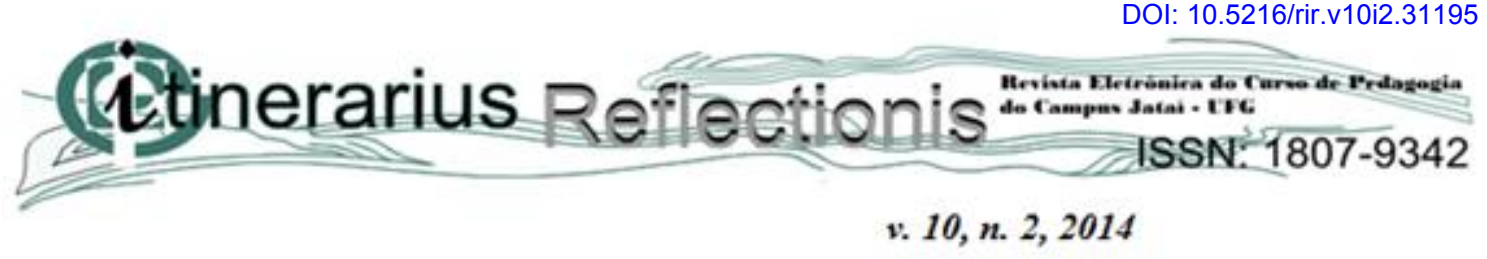

crenças pessoais sobre as causas responsáveis por esses eventos, sejam eles referentes às suas próprias vidas ou à vida de outros (TOLLEFSON, 2000).

Em contexto escolar, os estudos baseados nessa teoria tiveram início com Weiner (1979; 1985). Para o autor, alunos geralmente atribuem o sucesso e o fracasso em tarefas escolares à inteligência/capacidade, ao esforço, à dificuldade da tarefa e à sorte. Entretanto, como as causas concebíveis para sucesso e fracasso são inúmeras, Weiner (1985) sugeriu um esquema de classificação das atribuições, definindo a existência de três dimensões: a internalidade (causas internas ou externas ao sujeito), a estabilidade (causas estáveis ou instáveis) e a controlabilidade (causas controláveis ou incontroláveis pelo sujeito).

Pode-se dizer, por exemplo, que a capacidade e o esforço são causas internas ao sujeito, ao passo que a influência do professor, da tarefa e da família são externas. Atribuições à capacidade e à família poderiam ser tidas como estáveis, enquanto que esforço e atenção seriam instáveis. Em geral, a capacidade, sorte e influência do professor são consideradas incontroláveis, mas, por outro lado, o esforço seria uma causa controlável pelo sujeito (BORUCHOVITCH, 1994; BORUCHOVITCH \& MARTINI, 1997; MARTINI \& DEL PRETTE, 2005).

Segundo Weiner $(1979 ; 1985)$, as atribuições de causalidade para o sucesso e o fracasso escolar, interpretadas nas dimensões da causalidade, influenciam as expectativas, as emoções, os sentimentos, a motivação para a aprendizagem e o desempenho dos alunos. A estabilidade de uma causa, por exemplo, determina as expectativas de sucesso ou de fracasso futuro. A internalidade influencia as reações afetivas, a auto-estima, o orgulho e o autoconceito. A controlabilidade exerce efeitos diversos sobre as expectativas, a motivação e as emoções.

Em situações de fracasso pessoal, por exemplo, a estabilidade da causa pode resultar na redução da expectativa de sucesso futuro e em níveis mais altos de ansiedade, o inverso ocorrendo quando a causa é tida como instável. Causas estáveis e internas ao fracasso geram sentimentos de incompetência e vergonha e, em longo prazo, podem levar a depressão e ao desamparo. Causas controláveis de fracasso suscitam sentimentos de culpa, ao passo que as incontroláveis resultam em vergonha. Quando se trata de sucesso, as causas internas e estáveis geram sentimentos de orgulho e competência, como também se associam a baixos níveis de ansiedade (MARTINI \& DEL PRETTE, 2005). 


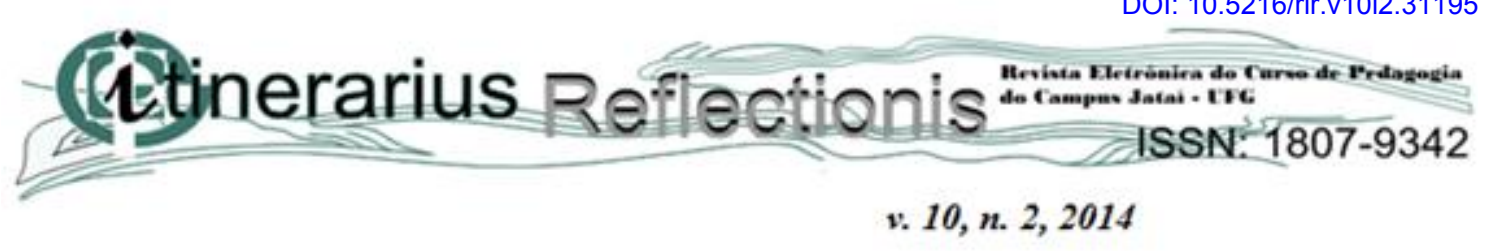

Cabe ressaltar que, de acordo com a teoria (WEINER, 1979; 1985), o modo como os indivíduos interpretam as atribuições nas dimensões da causalidade é mais importante na determinação do comportamento de realização do que as causas em si. Apesar das diferenças individuais, há um consenso geral quando se distingue causas internas ou externas, instáveis ou estáveis e controláveis ou incontroláveis (WEINER, 1994).

Para Weiner $(1979 ; 1985 ; 2006)$, a sequência motivacional integra, portanto, o pensamento, o sentimento e a ação do indivíduo, sendo as emoções a ponte entre os pensamentos e o comportamento (WEINER, 2006). Como descrito em Boruchovitch e Martini (1997), essa sequência tem início com um resultado que o indivíduo interpreta como positivo ou negativo. As primeiras reações emocionais emergentes são as emoções dependentes do resultado e independentes das causas. Depois de uma vitória, o vitorioso se sente feliz não importa se a causa foi esforço, sorte ou outra qualquer. A derrota é, em geral, acompanhada de sentimentos de tristeza. Em seguida, inicia-se uma procura pelas causas do resultado alcançado. Quando encontrada, a causa é interpretada pelo sujeito no espaço dimensional (internalidade, controlabilidade e estabilidade). As expectativas, as emoções e o comportamento do indivíduo são, então, influenciados por esta interpretação da causa.

Embora seu início tenha se concentrado nos estudos sobre como os próprios indivíduos interpretam suas experiências de sucesso e fracasso escolar, em uma abordagem com foco intrapessoal, a teoria da atribuição de causalidade se mostra também relevante na perspectiva interpessoal, ou seja, para a compreensão da motivação social, enfatizando fenômenos sociais importantes, tais como: reações a estigmas, a pobreza, a rótulos, bem como o comportamento agressivo, o altruísmo, o comportamento de ajuda, a atribuição de punição entre outros (WEINER, 2006; WEINER, OSBORNE \& RUDOLPH, 2011; WEINER, 2011). As investigações sobre as atribuições de causalidade relativas ao desempenho social e/ou acadêmico por outros significativos compõem uma das vertentes do modelo de Weiner, denominada Teoria da Motivação Interpessoal (WEINER, 2006).

O modelo atribucional prevê, portanto, a existência de duas teorias interrelacionadas: a Teoria da Motivação Intrapessoal e a Teoria da Motivação Interpessoal (WEINER, 2000; 2006; 2011). A Teoria Intrapessoal visa, pois, descrever pensamentos e sentimentos autodirigidos, identificar e analisar como as pessoas interpretam suas próprias experiências de 


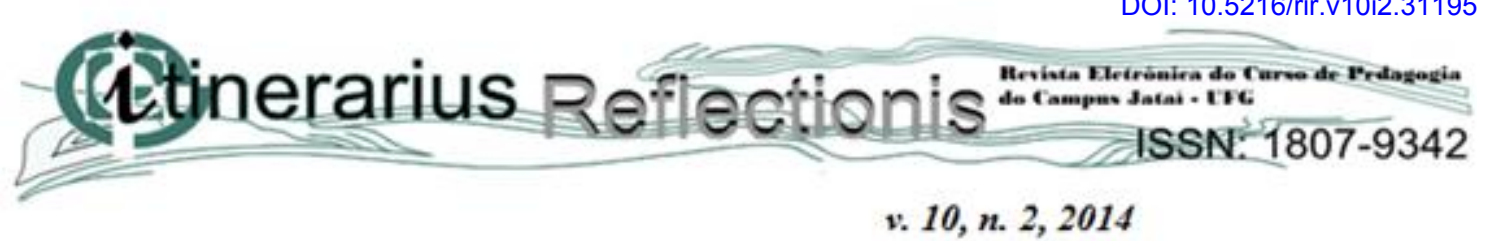

v. 10, n. 2,2014

sucessos e fracasso. Esse modelo teórico pode ser representado pela metáfora de que as pessoas são cientistas em busca de explicações sobre os eventos que vivenciam.

Pode-se citar um estudante que recebe uma nota baixa em uma prova de matemática e compreende que sua nota foi resultado de sua falta de capacidade nessa matéria. A falta de capacidade ou aptidão é tradicionalmente vista como uma causa interna, incontrolável e estável. Ao atribuir a falta de capacidade para o fracasso vivido, esse aluno pode sentir vergonha, ter prejuízos em sua auto-estima e no seu autoconceito acadêmico, além de ter reduzidas as suas expectativas de sucesso futuro. A compreensão desses pensamentos e sentimentos auto-dirigidos e suas consequências para a motivação à realização, constituem o foco da teoria intrapessoal da motivação.

Há uma vasta literatura dando suporte às premissas do modelo atribucional em sua perspectiva intrapessoal. Não restam dúvidas que resultados favoráveis ou desfavoráveis, respectivamente, dão origem a emoções positivas e negativas, que eventos indesejados e/ou inesperados levam o indivíduo a realizar a pesquisa sobre as causas responsáveis pela situação vivida, que a definição dessa causa depende de um conjunto de antecendentes (normas sociais, história passada, esquemas de crenças e preconceitos), como, também, que o locus, a estabilidade e a controlabilidade da causa são as dimensões principais e determinam fortemente as emoções vividas (WEINER, 2010).

Já a Teoria da Motivação Interpessoal focaliza os sentimentos e pensamentos que as pessoas possuem em relação ao comportamento social e aos sucessos e fracassos do outro que, por sua vez, influenciam a motivação e desempenho social de ambos os integrantes da relação. A metáfora utilizada para demonstrar as implicações dessa teoria é de que a pessoa é um juíze a vida uma corte. Como um juiz em sua corte, o ser humano nas mais diversas situações sociais que participa, ele observa e julga as ações dos demais, atribuindo-lhes sentenças como culpado ou inocente, inferindo a responsabilidade e/ou intencionalidade pelas ações, identificando atenuantes e atribuindo suas respectivas punições. Tópicos como comportamento de ajuda, agressão, punição, negligência, estigmatização e suas relações com as atribuições de causalidade são alguns dos temas centrais examinados nesse modelo (WEINER, 2000; 2004; 2006; 2011).

Weiner, Osborne e Rudolph (2011) conduziram um estudo para avaliar a reação de indivíduos com diferentes ideologias políticas à pobreza e a disposição em oferecer ajuda. Os 


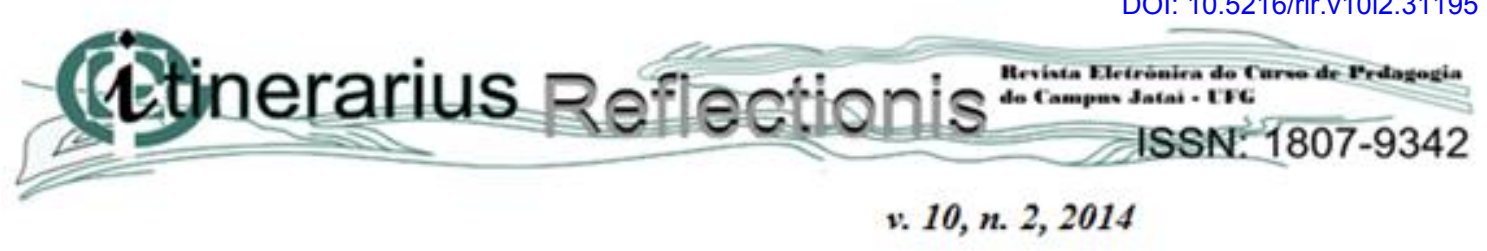

resultados indicaram que, quando pessoas são tidas como responsáveis pela sua situação de pobreza, em virtude de causas como: abuso de álcool e drogas, preguiça, falta de habilidade, de organização e de esforço, entre outras, uma interpretação dominante para o grupo político de conservadores da cultura norte-americana, elas provocam raiva e negligência. Em contraste, aqueles vistos como não responsáveis pela sua dificuldade financeira e sim vítimas de um sistema socioeconômico melhor caracterizado pela carência de boas escolas, pela falta de oportunidade, pelo preconceito, pela discriminação, bem como por doenças e deficiências, uma visão predominantemente apoiada pelos liberais, observa-se a presença da compaixão e a disponibilidade em ajudar. Para os autores, esta análise pode ser estendida para outros fenômenos, como as reações ao desempenho mal sucedido no contexto educativo, ao aborto e ao estupro.

Observa-se, portanto, que o processo de atribuição de causalidade envolve um julgamento moral, valores e princípios éticos de um indivíduo (Weiner, 2006). Ajudar aos pobres é uma questão moral, mas a avaliação moral diz respeito ao destinatário alvo da ajuda e não ao potencial doador. Quando um indivíduo julga, baseado em seus valores, que a pobreza é resultado de causas internas e controláveis pelo indivíduo (e nesse sentido, infere-se a noção de responsabilidade pela situação), sentimentos e comportamentos sociais-aversivos são eliciados. Em contrapartida, se a situação de pobreza é decorrente de causas incontroláveis e externas ao outro, sentimentos e comportamentos pró-sociais são observados (RUDOLPH, ROESCH, GREITEMEYER \& WEINER, 2010; WEINER, OSBORNE \& RUDOLPH, 2011; WEINER, 2006).

Em contexto escolar, a compreensão desses processos é de suma importância, não somente pelos benefícios associados ao processo educacional, especificamente (DEL PRETTE, PAIVA \& DEL PRETTE, 2005), mas também, para o entendimento das relações humanas, uma vez que a sala de aula, de acordo com Weiner (2006), pode ser considerada como um microcosmo da realidade.

A Teoria da Motivação Interpessoal é bastante útil para a investigação de como professores atribuem causas e compreendem o desempenho acadêmico e social de seus alunos, como alunos percebem os desempenhos de seus pares e quais são as consequências dessas avaliações para a qualidade das relações professor-aluno, aluno-aluno, para a motivação, desenvolvimento, aprendizagem e desempenho acadêmico, bem como para a prática docente 


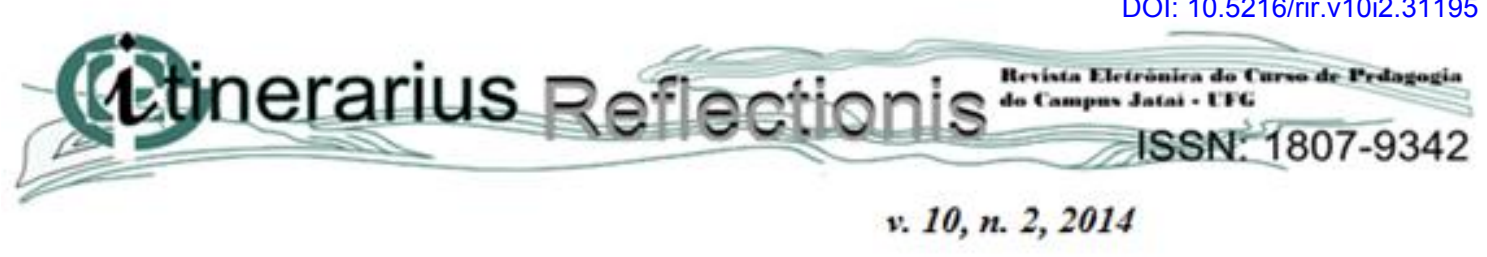

(FERREIRA, ASSMAR, OMAR, DELGADO, GONZÁLEZ, SOUZA \& CISNE, 2002; GAMA \& JESUS, 1994; LEITE, 1988; MALUF \& BARDELLI, 1991; NEVES E ALMEIDA, 1996; PAIVA \& DEL PRETTE, 2009; STIPEK, 1981, 1984; WEINER, 2000; 2006; 2011).

As experiências de sucesso e fracasso escolar não acontecem em um ambiente vazio. Pelo contrário, elas ocorrem em um contexto rico em relações sociais, que afetam e são afetadas por essas experiências. Colegas, professores, pais, educadores fazem parte desse contexto, experimentam emoções como alegria e tristeza pelo desempenho daqueles com quem convivem, podem expressar raiva ou pena, podem recompensar, punir, rotular, ajudar ou simplesmente negligenciar o outro e suas necessidades. O conhecimento dessas reações sejam elas individuais ou de grupo ao desempenho social e/ou acadêmico do outros, constitui o foco dos estudos e análises baseadas na Teoria Interpessoal da Motivação de Weiner (WEINER, 2000; 2006, 2011).

Por exemplo, se o professor compreender que um fracasso vivido pelo seu aluno foi devido à falta de esforço, uma causa frequentemente avaliada como controlável pelo indivíduo ("ele poderia ter estudado"), muito provavelmente esse aluno será visto como responsável pelo seu próprio fracasso. Do mesmo modo, se um aluno agrediu alguém intencionalmente ou tenha tido um mau desempenho em uma prova por ter sentido preguiça de estudar, esse aluno também será visto como responsável pelo seu próprio desempenho. Controlabilidade e responsabilidade pelo fracasso obtido geralmente suscitam emoções como raiva/indignação, resultando em comportamentos de repressão, punição e até mesmo agressão (WEINER, 1995; 2000; 2004; 2006).

Entretanto, caso o professor identifique condições atenuantes da "culpa" do aluno, esse mesmo padrão atribucional pode gerar consequências diferentes das previamente descritas. Por exemplo, um aluno que não estudou para a prova porque seus pais estavam doentes e ele precisou ajudar nas tarefas de casa, provavelmente, ao invés de sentimentos de raiva e comportamentos de punição e reprimenda, suscitará sentimentos de pena e compaixão em seu professor, que tenderá a agir de maneira mais pró-social junto ao seu aluno, oferecendo ajuda e novas oportunidades de desempenho (WEINER, 2000; 2006).

Em contrapartida, se o fracasso desse aluno for atribuído à falta de capacidade, uma causa tradicionalmente vista como incontrolável, que não pode ser alterada intencionalmente e pela vontade do indivíduo, esse aluno não será considerado responsável ou culpado pelo 


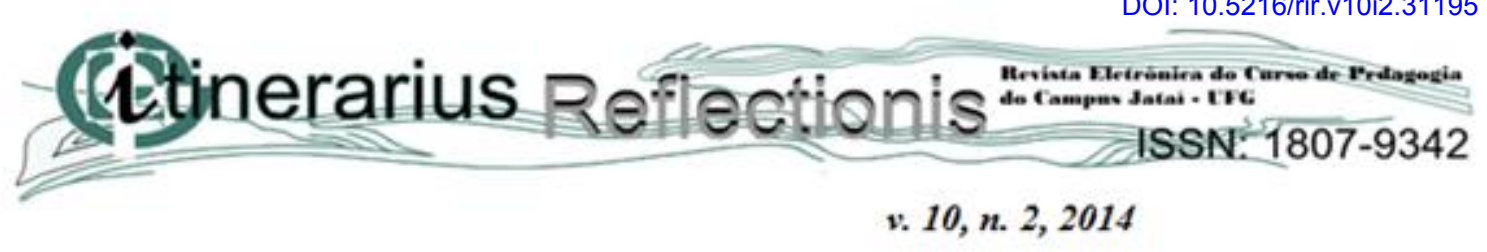

fracasso. Falta de controle e responsabilidade por desempenhos mal sucedidos tendem a suscitar pena e reações mais pró-sociais. Todavia, diferenças podem ser encontradas e esse padrão atribucional gerar desprezo, desdém e negligência (WEINER, 2000; 2006).

Rótulos e estigmas são, também, bastante frequentes em contexto de sala de aula e podem ser avaliados com base nas mesmas propriedades das dimensões de causalidade (GUERRA, 2009; WEINER, 2006). Não é incomum encontrar professores que nomeiam seus alunos com termos como "bagunceiros", "indisciplinados", "bonzinhos", "cooperativos", "desatentos", "agressivos", "brilhantes" entre outros. Esses rótulos se relacionam às profecias auto-realizáveis, ou seja, geram expectativas positivas ou negativas em relação ao indivíduo, que, de uma forma ou de outra, tendem a se realizar, bem como a influenciar, sobremaneira nas relações sociais daqueles que recebem esses rótulos (ROSENTHAL \& JACOBSON, 1968).

Há um conjunto de evidências de que crianças, por exemplo, tendem a reagir diferentemente aos colegas que apresentam algum tipo de característica que os façam se comportar de modo diverso aos padrões usuais. Crianças agressivas ou hiperativas são avaliadas como menos queridas pelos seus pares do que aquelas com deficiências mentais ou físicas (JUVONEN, 1991; SIGELMAN \& BEGLEY, 1987).

Rótulos associados ao gênero também influenciam as atribuições que adultos fazem para meninos e meninas. Pais geralmente consideram que meninos são naturalmente inclinados a serem mais talentosos em matemática e atribuem o sucesso de seus filhos nessa matéria à capacidade e de suas filhas ao esforço. O padrão oposto é encontrado para a aprendizagem do inglês (DUNTON, MCDEVITT, \& HESS, 1988; JACOBS \& ECCLES, 1992; YEE \& ECCLES, 1988).

Estereótipos de raça afetam igualmente as atribuições. Reyna (2000) identificou que quando professores consideram que alunos provenientes de um determinado grupo étnico tido como supostamente "preguiçoso", eles tendem a atribuir o baixo desempenho à falta de esforço, sentem raiva pelo aluno e se recusam a oferecer ajuda ao seu aluno. Mas, esses professores sentem mais compaixão e trabalham mais arduamente junto àqueles estudantes que são provenientes de grupos étnicos vítimas da discriminação racial ou da pobreza, causas consideradas incontroláveis pelo sujeito. Para Weiner (2006), a sentença imposta pelos “juízes”, portanto, depende, sobretudo, da avaliação da controlabilidade da causa, bem como 


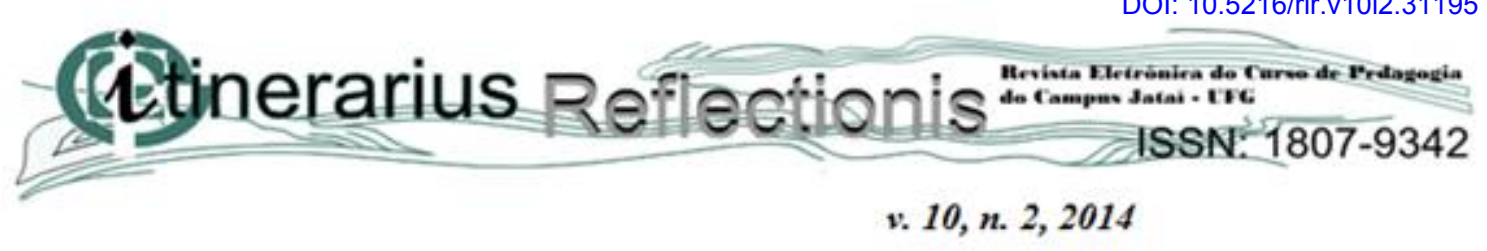

da responsabilidade e da intencionalidade do indivíduo sobre seu estado negativo e sobre suas consequências comportamentais.

Portanto, do mesmo modo que na perspectiva intrapessoal, esse modelo prevê que a sequência motivacional é iniciada pelo resultado de um desempenho. Novamente, começa-se a busca pelas causas responsáveis pelo sucesso ou fracasso, porém, nesse caso, feita por um observador, tal como: professor, colegas, pais, entre outros. Essa causa é interpretada no espaço dimensional, sendo a dimensão controlabilidade e também os conceitos de responsabilidade e intencionalidade pelas ações e resultados do evento de suma importância para o contexto interpessoal. Essa interpretação suscita emoções específicas em relação ao aluno e comportamentos sociais compatíveis com essa avaliação atribucional. Vale ressaltar que as causas atribuídas pelo agente podem coincidir ou não com aquelas feitas pelo observador.

No Brasil, os estudos sobre atribuição de causalidade se concentraram predominantemente na perspectiva intrapessoal da teoria atribucional e visaram identificar, sobretudo, como alunos atribuem as causas responsáveis pelos seus sucesso e fracasso (BORUCHOVITCH, 2001; BORUCHOVITCH, 2004; BORUCHOVITCH \& MEDNICK, 2000; PAIVA \& BORUCHOVITCH, 2010; TALIULI,1982; NUNES,1990; BORUCHOVITCH, 1997; PICCININI, 1987, 1989, 1990; RODRIGUES, 1984; 1992). Os estudos relativos à teoria da motivação interpessoal, no entanto, são bem mais escassos em nosso meio, porém não menos relevantes e necessários, dadas as suas importantes implicações educacionais (MARTINI \& DEL PRETTE, 2002; PAIVA \& DEL PRETTE, 2009).

Em uma revisão dos estudos nacionais sobre atribuições de causalidade de professores para o desempenho acadêmico dos seus alunos, Martini e Del Prette (2005) identificaram que eles tendem a atribuir o fracasso escolar predominantemente ao próprio aluno e à sua família e a esperar pouco sucesso dos mesmos, expressando uma compreensão do fracasso como decorrente de causas estáveis (NUNES, 1990; NEVES E ALMEIDA,1996; TALIULI, 1982). Essas crenças estavam associadas a uma baixa expectativa de sucesso e alta de fracasso. Martini e Del Prette (2002) e Paiva e Del Prette (2009) também encontraram uma tendência das professoras a atribuírem aos próprios estudantes a responsabilidade pelo sucesso e fracasso escolar, embora reconheçam a ação docente como fator de desenvolvimento e aprendizagem dos alunos. 


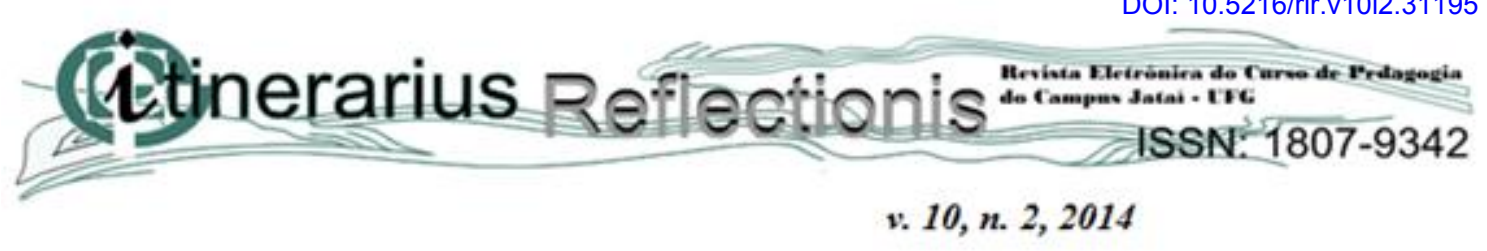

Gama e Jesus (1994) investigaram as atribuições de causalidade e as expectativas de professores sobre o desempenho escolar de seus alunos de escolas públicas. Verificou-se um deslocamento das atribuições para o fracasso escolar do âmbito da escola e do professor para o campo de responsabilidade individual do aluno e de sua família (mais especialmente o interesse, esforço e condições econômicas de seus integrantes). Os alunos considerados pelo professor como menos inteligentes não apenas geravam expectativas de que o seu desempenho final seria baixo, como também eram sistematicamente reprovados. Em estudos semelhantes, Maluf e Bardelli (1991) e Neves e Almeida (1996) demonstraram que, em geral, professoras do ensino fundamental atribuem o mau rendimento escolar dos seus alunos a causas familiares e a problemas de saúde física. Essas expectativas acabam por se transformar em teorias acabadas sobre o desempenho dos alunos e em profecias de auto-realização.

\section{A Teoria Atribucional de Weiner e o papel das emoções na motivação acadêmica e social.}

Embora tradicionalmente as pesquisas educacionais tenham se concentrado nos aspectos cognitivos do processo educacional, como a memória, a atenção, o raciocínio, a percepção e a linguagem, entre outros, em detrimento dos seus aspectos afetivos, a relevância de se compreender os sentimentos e as emoções em contexto educacional é, atualmente, indiscutível (OATLEY \& NUNDY, 2000). Nessa perspectiva, constata-se que as contribuições do modelo atribucional para análise das emoções e suas consequências no desempenho acadêmico e social de professores e alunos são promissoras para o campo das investigações e intervenções educacionais.

No modelo atribucional, as emoções assumem um papel fundamental, pois se relacionam fortemente às atribuições de causalidade e são reguladoras do comportamento humano (WEINER, 1985, 2006; 2011). Para Weiner (1979; 1985; 2006; 2011), a influência das atribuições de causalidade na motivação social e acadêmica é sempre mediada pelas emoções, que atuam como pontes entre as atribuições e o comportamento subsequente.

O papel de mediação exercido pelas emoções nas atribuições e no comportamento futuro torna-se evidente quando se observa a sequência motivacional proposta por Weiner (1985), tanto no que se refere à perspectiva intra como interpessoal da motivação. Como já mencionado anteriormente, no que se refere ao modelo intrapessoal, a sequência motivacional 


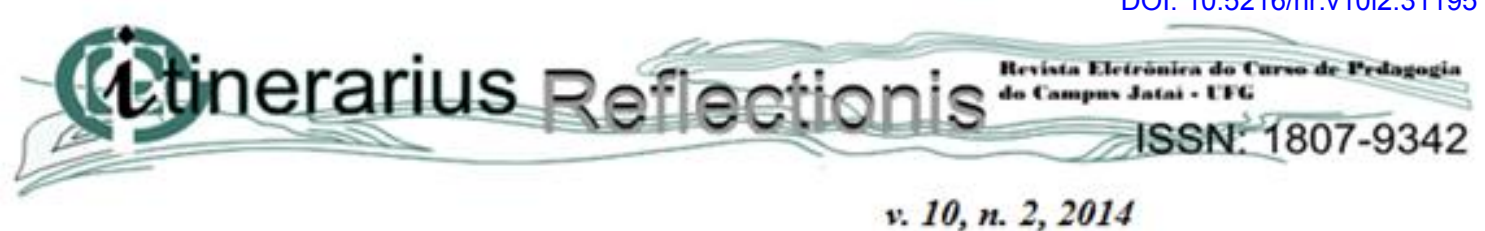

v. 10, n. 2,2014

começa com o resultado de um desempenho que pode ser tanto positivo quanto negativo. Em seguida, emoções diretamente relacionadas ao resultado obtido, seja ele bem ou mal sucedido, podem surgir, tais como tristeza ou alegria. Essas duas emoções, em geral, dependem do resultado em si, isto é não dependem necessariamente da causa. Em seguida, dá-se início à busca pelas causas responsáveis pelo sucesso ou fracasso obtido, numa tentativa do indivíduo de compreender, prever e controlar seu desempenho futuro. Quando a causa é identificada e interpretada no espaço dimensional, emoções específicas e dependentes das atribuições de causalidade emergem, passando a exercer influência no comportamento subsequente.

Pode-se mencionar, por exemplo, quando um aluno atribui o sucesso em uma tarefa à capacidade, uma causa interna e estável, ele pode sentir-se orgulhoso e competente. Mas, quando um fracasso é atribuído à falta de capacidade, sentimentos como raiva, vergonha, tristeza e desprezo por si mesmo poderiam surgir, o que, em longo prazo, traria sérios comprometimentos à sua motivação e desempenho escolar (WEINER, 2004; MARTINI \& DEL PRETTE, 2004).

Martini e Boruchovitch (1999) revisaram as possíveis relações entre as atribuições de causalidade, as dimensões da causa e as emoções, descritas na literatura da área. Em síntese, as autoras identificaram que, quando as causas de fracasso pessoal são consideradas controláveis, sentimentos de culpa podem surgir, ao passo que causas incontroláveis de fracasso geram sentimentos de vergonha. Depressão, apatia, resignação, desamparo e desânimo são relatados, sobretudo na presença de atribuições internas e estáveis para fracasso. Enquanto que o sucesso atribuído a causas estáveis associa-se a baixos níveis de ansiedade, em situações de fracasso, a estabilidade da causa se relaciona positivamente a níveis mais altos de ansiedade.

Em relação à perspectiva interpessoal, a sequência motivacional também se inicia pela constatação feita por um observador que pode ser um professor, colegas, pais, entre outros, de que o indivíduo obteve um resultado positivo ou negativo. Emoções como tristeza ou alegria, diretamente relacionadas à natureza do desempenho observado podem surgir e são seguidas pela busca das causas responsáveis pelo resultado obtido. Com a identificação da causa e sua respectiva interpretação nas dimensões da causalidade, surgem emoções específicas e dependentes das atribuições, tais como pena, gratidão, indignação, desprezo, admiração. Essas 


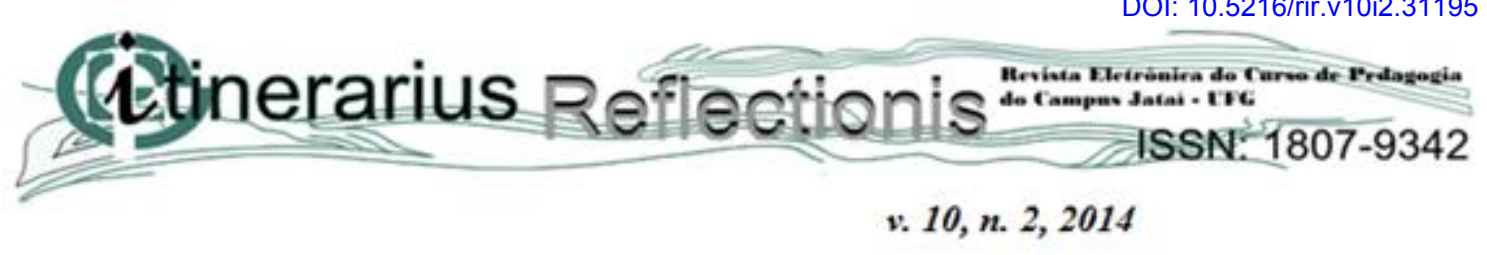

emoções sociais passam a exercer influência no comportamento subsequente de ambos os integrantes da relação.

Pode-se mencionar, por exemplo, um aluno que obteve um resultado ruim em uma das avaliações finas do curso por ter ficado seriamente doente na semana de provas, enquanto que outro aluno desempenhou-se mal nas provas por ter conversado muito nas aulas e não ter realizado as tarefas escolares. Em relação ao primeiro aluno, o professor pode compreender que fracassar por ter ficado doente é algo incontrolável pelo indivíduo e, nesse caso, sentimentos como pena e compaixão em relação ao aluno podem surgir, deixando o professor mais propenso ao comportamento de ajuda. Por outro lado, em relação ao segundo aluno, o fracasso obtido pela falta de atenção e compromisso com as tarefas escolares, causas frequentemente vistas como intencionais e controláveis pelo indivíduo, podem suscitar sentimentos de raiva e indignação no professor e, consequentemente, deixá-lo mais propenso a não oferecer a ajuda necessária, a reprimir ou ainda a punir o comportamento do aluno.

Em uma revisão de literatura, Martini e Boruchovitch (1999) constataram relações específicas entre um dado padrão atribucional e as emoções sociais. A raiva, por exemplo, surge quando a causa de um evento negativo é percebida como possível de ser controlada por outra(s) pessoa(s), enquanto a pena aparece quando o fracasso é decorrente de uma causa incontrolável e não intencional para aquele que fracassa. A gratidão, por sua vez, é observada quando a causa do sucesso é devido à ajuda de alguém. Além dessas emoções, podem ser mencionadas a admiração, a culpa e a indignação. A primeira é decorrente da constatação feita pelo observador de que um indivíduo alcançou um resultado positivo em função de suas habilidades. Já a culpa e a indignação, em geral, são consequências da interpretação de que um resultado negativo foi fruto de uma ação intencional e controlável pelo outro (WEINER, 2006).

Neste sentido, segundo Weiner (2006), as emoções devem ser entendidas tanto como um fenômeno intrapsíquico como social, dependendo de seus antecedentes e indicadores. Enquanto, por um lado, alguns estados afetivos podem estar associados a alterações fisiológicas e/ou hormonais e compreendidas do ponto de vista do indivíduo, como, por exemplo, o medo de altura. Por outro lado, emoções como gratidão e pena envolvem claramente experiências sociais e exercem impacto considerável no contexto das relações interpessoais. 


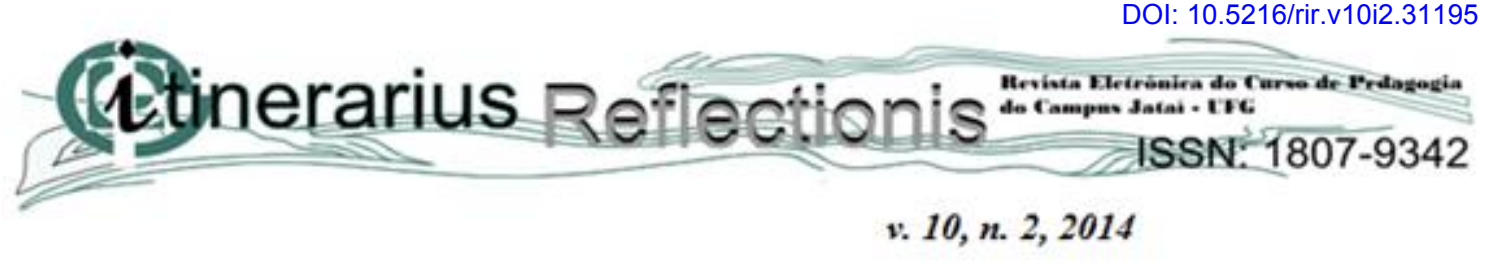

Para Weiner (2010) as atribuições causais são responsáveis por uma extensão surpreendente da vida emocional dos indivíduos e há uma vasta literatura internacional dando suporte a estas afirmações (WEINER, 1985, 1986, 1995). No entanto, como alertam Martini e Del Prette (2004), no Brasil, os estudos que articulam as atribuições e as emoções são ainda incipientes. Entretanto, dada a importância de sua influência no comportamento humano, as autoras afirmam ser fundamental o investimento de esforços por parte de pesquisadores e educadores, no sentido de se compreender mais profunda e amplamente como se dá a relação entre essas variáveis cognitivas e afetivas em contexto educacional. Mais precisamente, pode se dizer que, na esfera educativa, predominaram estudos, em nosso meio, mais orientados para as investigações de estados afetivos como a ansiedade e a depressão (COSTA \& BORUCHOVITCH, 2010, CRUVINEL \& BORUCHOVITCH, 2011; GIACOMINI \& HUTZ, 2006). BORUCHOVITCH E BORTOLLETO (2010) destacam que há muito que se avançar na área de avaliação psicoeducacional, em direção à construção de instrumentos nacionais de medida dessas e de outras emoções humanas mais associadas à escolarização formal.

\section{Considerações finais}

Pode-se afirmar, portanto, que as atribuições de causalidade dos professores afetam as relações professor-aluno e, por esta via, a aprendizagem e o desenvolvimento socioemocional dos alunos, o que torna relevante e necessária a concentração de esforços no sentido de identificar e intervir sobre esses aspectos em nosso meio, sobretudo, quando se leva em consideração o reduzido número de pesquisas nessa área com professores e alunos brasileiros do ensino fundamental (BORUCHOVITCH, 2004; GAMA \& JESUS, 1994; MALUF \& BARDELLI, 1991; MARTINI \& BORUCHOVITCH, 2001; NEVES \& ALMEIDA, 1996; MARTINI \& DEL PRETTE, 2002; PAIVA \& DEL PRETTE, 2009).

De acordo com o modelo da motivação interpessoal de Weiner, as atribuições de causalidade (por exemplo, capacidade e esforço) para um determinado evento, bem como os julgamentos de controle e responsabilidade sobre essas causas são determinantes essenciais das emoções sociais e influenciam sobremaneira a motivação social. Na perspectiva atribucional, grande parte da motivação social resulta diretamente de sentimentos que, por sua 


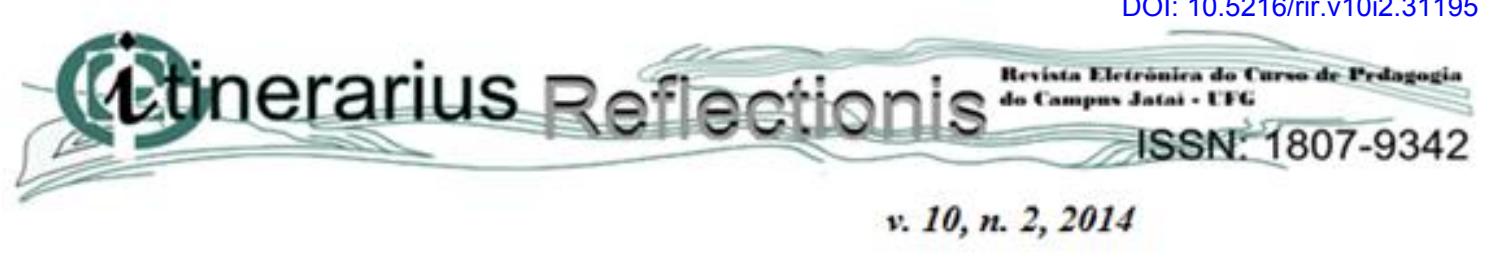

vez, são guiados por pensamentos ou, mais especificamente, pelas avaliações atribucionais e percepções de responsabilidade.

Embora se identifiquem na literatura nacional alguns estudos na perspectiva atribucional, como descrito anteriormente, a complexidade do processo motivacional na perspectiva intrapessoal e interpessoal, ou seja, a sequência evento-atribuições-emoções-ação na íntegra, tanto do ponto de vista de professores como dos seus alunos ainda não foi completamente investigada. Quando um professor atribui o fracasso do seu aluno à falta de capacidade, uma causa incontrolável, as relações com seu aluno serão permeadas pela pena e pela compaixão. Essa comunicação emocional reforça a percepção do aluno de que ele não é capaz, gerando sentimentos de vergonha e humilhação. Por outro lado, se o aluno fracassa por falta de esforço, o professor poderá sentir raiva, sinalizando a compreensão de que o outro é responsável pela falha e que o fracasso poderia ser evitado, gerando culpa no aluno.

É fundamental, portanto, que não somente as causas atribuídas pelos professores ao sucesso e fracasso de seus alunos sejam investigadas, mas também que sejam conhecidas e examinadas a complexidade das relações entre as atribuições docentes e discentes, as emoções a elas associadas e a gama possível de ações subsequentes desse professor, que podem incluir a seleção de punições e reprimendas específicas para o aluno, o oferecimento de ajuda ou negligência, o estabelecimento ou fortalecimento de rótulos e estigmas, a maximização ou comprometimento da qualidade das relações interpessoais em sala de aula, entre outras consequências. A relevância dessas investigações está, sobretudo, na aplicabilidade do modelo teórico atribucional na modificação das crenças causais e, por essa via, a subsequente alteração nos comportamentos. Esses programas focalizam as crenças disfuncionais, que atuam de modo a impedir ou dificultar o processo motivacional e o desempenho do indivíduo. Geralmente, eles são orientados à alteração das crenças que geram dúvidas sobre a capacidade do indivíduo de enfrentar a tarefa (causas internas e estáveis para o fracasso e externas para o sucesso) para causas mais autorreguláveis, favorecendo, assim, a motivação (Weiner, 2010).

Espera-se que este artigo possa propiciar a educadores, professores e psicólogos escolares um conhecimento mais amplo sobre como as interpretações de professores e alunos sobre as causas responsáveis pelas experiências de sucesso e fracasso escolar associam-se a outras variáveis cognitivas e afetivas, tais como rótulos, emoções, expectativas, percepções de competência, punição, entre outras. Acredita-se que a compreensão da estrutura motivacional 


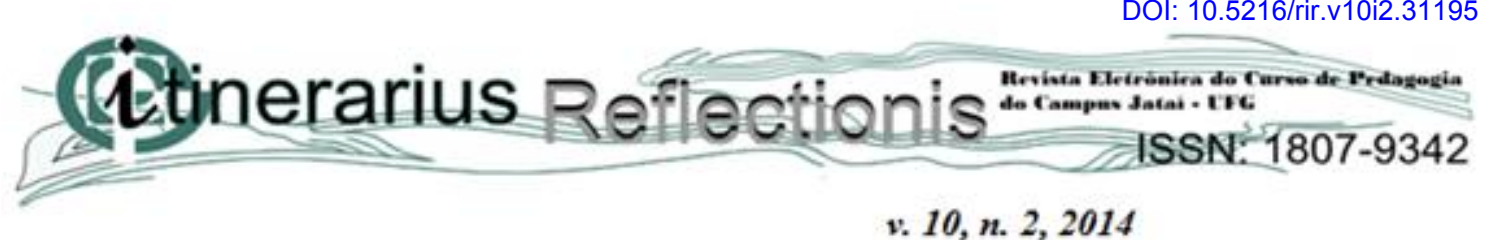

v. 10, n. 2,2014

proposta pelo modelo atribucional completo, isto é, evento-atribuições-emoçõescomportamento associadas às relações professor-aluno é promissora e oferece subsídios importantes para que intervenções atribucionais sejam conduzidas, com vistas a promover novas condições geradoras de um contexto mais favorável ao sucesso escolar, que levem a comportamentos pró-sociais e contribuam para a melhoria qualidade das relações em sala de aula.

\section{REFERÊNCIAS}

ALMEIDA, L. S.; GUISANDE, M. A. (2010). Atribuições causais na explicação da aprendizagem escolar. In: Boruchovitch, E.; Bzuneck, J. A.; Guimarães, S. E. R. (Orgs). Motivação para aprender: aplicações no contexto educativo. Petrópolis: Vozes.

BERRY, R. A. W. (2006). Beyond strategies: teacher beliefs and writing instruction in two primary inclusion classroom. Journal of Learning Disabilities, 39(1), 11-24.

BORUCHOVITCH, E. (1994) As variáveis psicológicas e o processo de aprendizagem: Uma contribuição para a psicologia escolar. Psicologia: Teoria e Pesquisa, 1, 129-139.

BORUCHOVITCH, E.; MEDNICK, B. R. (1997). Cross-cultural differences in children's concepts of health and illness. Rev. Saúde Pública, 31 (5): 448-56.

BORUCHOVITCH, E. \& MARTINI, M. L. (1997). As atribuições de causalidade para o sucesso e o fracasso escolar e a motivação para a aprendizagem de crianças brasileiras. Arquivos Brasileiros de Psicologia, 49(3), 59-71.

BORUCHOVITCH, E. \& MEDNICK, B. R. (2000) Causal Attributions in Brazilian Children's reasoning about health and illness. Revista de Saúde Pública, 5 (34), 484-490.

BORUCHOVITCH, E. (2001). Conhecendo as crenças de inteligência, esforço e sorte em tarefas escolares. Psicologia: Reflexão e Crítica, 14(3), 461-467.

BORUCHOVITCH, E. (2004). A study of causal attributions for success and failure in mathematics among brazilian students. Revista Interamericana de Psicologia, 38 (2), 53-60.

BORUCHOVITCH, E.; BORTOLETTO, D. (2010). Estratégias de regulação emocional. In: Santos, A.; Sisto, F. F.; Boruchovitch, E.; Nascimento, E. (Orgs.). Perspectivas em Avaliação Psicológica (pp. 271-292). São Paulo: Casa do Psicólogo. 


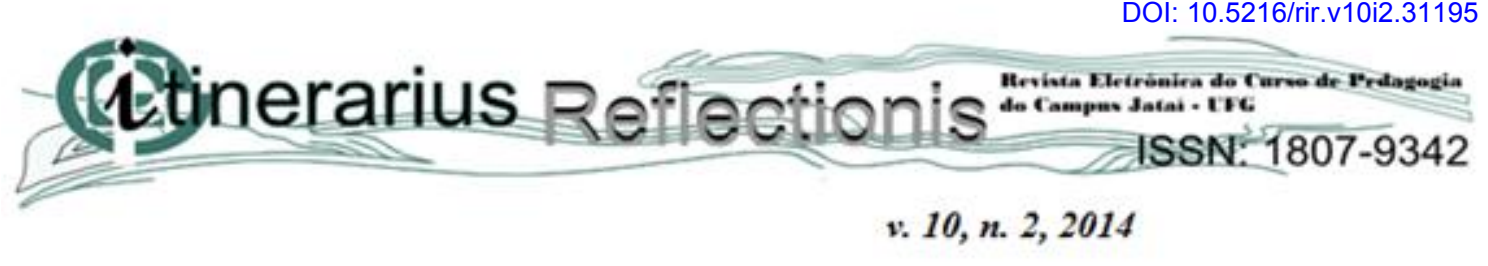

BRIGHTON, C. M. (2003). The effects of middle school teachers' beliefs on classroom practices. Journal for the Education of the Gifted, 27(2-3), 177-206.

CALDERHEAD, J. (1996) Teachers: beliefs and knowledge. Em: D.C. Berlinger \& R.C. Calfee (Orgs). Handbook of research on teaching. New York: McMillian.

COSTA, E. R.; BORUCHOVITCH, E. (2010). As Estratégias de Aprendizagem de Alunos Repetentes do Ensino Fundamental. Psicologia em pesquisa (UFJF), 4, 31-39.

CRUVINEL, M.; BORUCHOVITCH, E. (2011). Regulação emocional em crianças com e sem sintomas depressivos. Estudos de Psicologia (UFRN), 16, 219-226.

DEL PRETTE, Z. A. P., PAIVA, M. L. M., \& DEL PRETTE, A. (2005). Contribuições do referencial das habilidades sociais para uma abordagem sistêmica na compreensão do processo de ensino-aprendizagem. Interações, X(20), 57-72.

DUNTON, K. J., MCDEVITT, T. M., \& HESS, R. D. (1988). Origins of mothers' attributions about their daughters' and sons' performance in mathematics in sixth grade. Merrill-Palmer Quarterly, 34, 47-70

ERRINGTON, E. (2004). The impact of teacher beliefs on flexible learning innovation: some practices and possibilities for academic developers. Innovations in Education and Teaching International, 41(1), 39-47.

FERREIRA, M., ASSMAR, E., OMAR, A., DELGADO, H., GONZÁLEZ, A., SOUZA, M., \& CISNE, M. (2002). Atribuições de causalidade ao sucesso e fracasso escolar: Um estudo transcultural Brasil-Argentina-México. Psicologia: Reflexão e Crítica, 15(3), 515-527.

GAMA, E. M. P. \& JESUS, D. M. (1994). Atribuições e expectativas do professor: representações sociais na manutenção da seletividade social na escola. Psicologia: Teoria $e$ Pesquisa, 10(3), 393-410.

GANDA, D. R.; BORUCHOVITH, E. (2011). Atribuições de causalidade no Ensino Superior. Análise da produção científica. Estudos Interdisciplinares em Psicologia, 2(1), 2-18.

GIACOMINI, C. H.; HUTZ, C. S. (2006). Escala de afeto positivo e negativo para crianças: Estudos de construção e validação. Psicologia Escolar e Educacional, 10, 235-245.

GUERRA, M. A. S. (2009). Almas tatuadas. Aprendizagens sobre avaliação a partir da experiência. Sísifo. Revista de Ciências da Educação, Lisboa, 9, 101-114.

JACOBS, J. E., \& ECCLES, J. S. (1992). The influence of parent stereotypes on parent and child ability beliefs in three domains. Journal of Personality and Social Psychology, 63, 932944. 


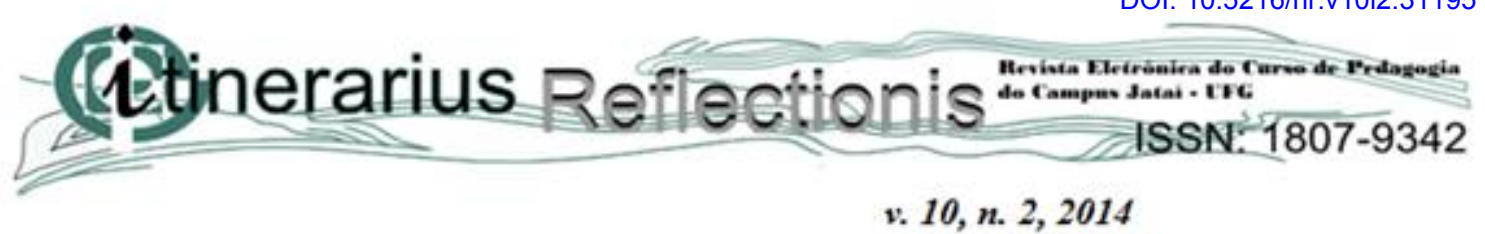

JUVONEN, J. (1991). Deviance, perceived responsibility, and negative peer reactions. Developmental Psychology, 27, 672-681.

LEITE, S. A DA S. (1988). O fracasso escolar no ensino de 1o grau. Revista Brasileira de Estudos Pedagógicos, 69(163), 510-540.

MALUF, M. R. \& BARDELLI, C (1991) Que valor o professor atribui a capacidade e resultado obtido pelos alunos em contexto de realização escolar? Arquivos Brasileiros de Psicologia, 36(4), 132-41.

MARTINI, M. L. \& BORUCHOVITCH, E. (2001). Atribuições de causalidade: a compreensão do sucesso e fracasso escolar por crianças brasileiras (pp.148-166). In: E. Boruchovitch \& Bzuneck, A. (Orgs). A motivação do aluno. Contribuições da psicologia contemporânea. Petrópolis: Vozes.

MARTINI, M. L. \& DEL PRETTE, Z. (2002). Atribuições de causalidade de professoras do ensino fundamental para o sucesso e o fracasso escolar dos seus alunos. Revista Interação em Psicologia, 6(2), 149-156.

MARTINI, M. L., \& BORUCHOVITCH, E. (2004). A teoria da atribuição de causalidade: Contribuições para a formação e atuação de educadores. Campinas: Alínea.

MARTINI, M. L., DEL PRETTE, Z. A. P. (2005). Atribuições de causalidade e afetividade de alunos de alto e baixo desempenho acadêmico em situações de sucesso e de fracasso escolar. Interamerican Journal of Psychology, 39(3), 355-368.

MIRANDA, L., \& ALMEIDA, L. S. (2009). As metas académicas como operacionalização da motivação do aluno. Educação Temática Digital, 10, 36-61.

MIRANDA, L. C. et al . (2012). Atribuições causais e nível educativo familiar na compreensão do desempenho escolar em alunos portugueses. Psico-USF, 17(1).

NEVES, M. B. J. \& ALMEIDA, S. F. C. (1996). O fracasso escolar na $5^{\text {a }}$ série, na perspectiva de alunos repetentes, seus pais e professores. Psicologia: Teoria e pesquisa, 12, 147-156.

NUNES, A. N. de A. (1990). Fracasso escolar e desamparo adquirido. Psicologia: Teoria e pesquisa, 6(2), 139-154.

OATLEY, K.; NUNDY, S. (2000). Repensando o papel das emoções na educação. In: Olson, D.; Torrance, N. (Orgs.). Educação e desenvolvimento humano (pp. 217-232). Porto Alegre: Artmed.

PAIVA, M. L. M. F., \& DEL PRETTE, Z. A. P.(2009). Crenças docentes e implicações para o processo de ensino e aprendizagem. Psicologia Escolar e Educacional, 13, 75-85. 


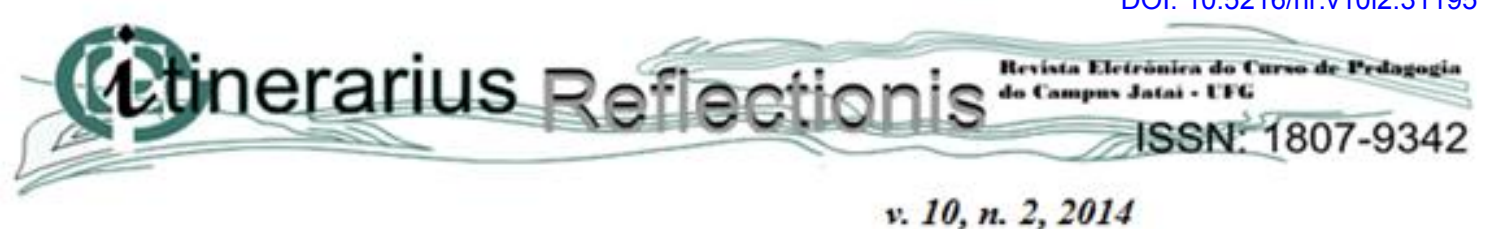

v. 10, n. 2,2014

PAIVA, M. L. M. F.; BORUCHOVITCH, E. (2010). Orientações motivacionais, crenças educacionais e desempenho escolar de estudantes do ensino fundamental. Psicologia em Estudo, 15(2), 381-389.

PAJARES, M. F (1992) Teacher's belief and educational research: cleaning up a messy construct. Review of Educational Research, 62(3), 307-332.

PICCININI, C.A. (1989). Atribuições de causalidade em crianças; alguns aspectos críticos. Psicologia: teoria e pesquisa, 5(1), 57-69.

PICCININI, C. (1990). Problemas metodológicos nas investigações sobre atribuições de causalidade para sucesso e fracasso em crianças. Arquivos Brasileiros de Psicologia, 42(1) 23-29.

REYNA, C. (2000). Lazy, dumb, or industrious: When stereotypes convey attribution information in the classroom. Educational Psychology Review, 12, 85-110.

RODRIGUES, A. (1984) Atribuicao de causalidade: Estudos brasileiros. Arquivos Brasileiros de Psicologia, 36(2), 5-20

Rodrigues, A. (1992) Estilo atribuicional e suas consequencias. Psico,23(1),23-32

ROSENTHAL, R. \& JACOBSON, L. (1968). Pigmalion in the classroom. New York: Holt, Rinehart e Winston.

SACRISTÀN, J. G. \& GOMES, A. (1998). Compreender e transformar o ensino. Porto Alegre: Artes Médicas.

SIGELMAN, C. K., \& BEGLEY, N. L. (1987). The early development of reactions to peers with controllable and uncontrollable problems. Journal of Pediatric Psychology, 12, 99-115.

STIPEK, D. (1981) Children's perception of their own and their classmates' ability. Journal of Educational Psychology, 73, 404-410.

STIPEK, D.J. (1984) The development of achievement motivation. In: R. Ames \& C. Ames (Eds), Research on Motivation in education (Vol, 145-174). New York: Academic Press.

TALIULI, N. (1982). Atribuição de causalidade em tarefas acadêmicas por alunos de nível sócio econômico baixo e desempenho diferente. Dissertação de Mestrado. Universidade Federal do Espírito Santo.

TOLLEFSON, N. (2000). Classroom applications of cognitive theories of motivation. Educational Psychology Review, 12 (1), 63-83.

WARFIELD, J., WOOD, T., \& LEHMAN, J. D. (2005). Autonomy, beliefs and the learning of elementary mathematics teachers. Teaching and Teacher Education, 21(4), 439-459. 


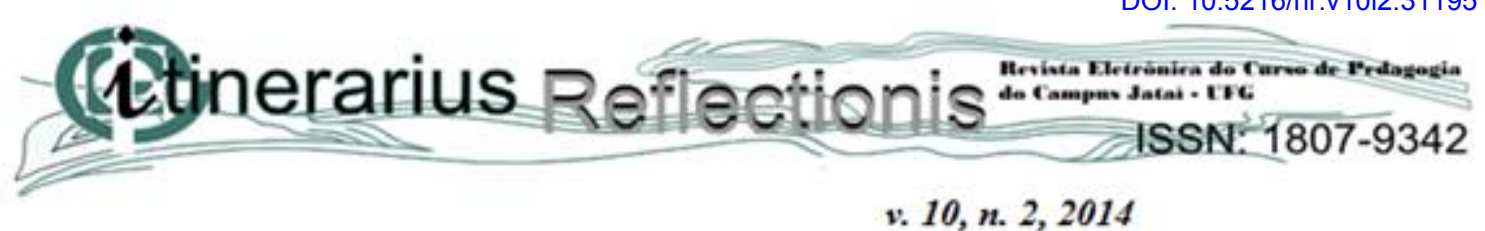

v. 10, n. 2,2014

WEINER, B. (1979). A theory of motivation for some classroom experiences. Journal of Educational Psycology, 71,3-25.

WEINER, B. (1985). An attributional theory of achivement motivation and emotion. Psycological Rewiew, 92(4), 548-573.

WEINER, B. (1994). Integrating social and personal theories of review achievement striving. Review of Educational Research, 64, 79-94.

WEINER, B. (2000). Intrapersonal and interpersonal theories of motivation from an attributional perspective. Educational Psychology Review, 12, 1-14.

WEINER, B. (2004) Attribution theory revisited: transforming cultural plurality into theoretical unity. Em: McInerney, D. M. \& Van Etten, S. (Orgs.). Big Theories Revisited. Greenwich, USA: Information Age Publishing, 13-29.

WEINER, B. (2006). Social motivation, justice and the moral emotionas. An attributional approach. Lawrence Erlbaum Associates.

WEINER, B. (2010). The Development of an Attribution-Based Theory of Motivation: A History of ideas. Educational Psychologist, 45(1), 28-36.

WEINER, B . (2011). Ultimate and proximal determinants of motivation given an attribution perspective and the metaphors guiding attribution theory. Group \& Organization Management, 36, 526-532.

WEINER, B., OSBORNE, D., \& RUDOLPH, U. (2011). An attributional analysis of reactions to poverty: The political ideology of the giver and the perceived morality of the receiver. Personality and Social Psychology Review, 15, 199-213.

RUDOLPH, U., ROESCH, S.C., GREITEMEYER, T. \& WEINER, B. (2004). Meta-analytic review of help giving and aggression from an attributional perspective. Cognition and Emotion, 18, 815-848.

WEIZS, T. (1999). O diálogo entre o ensino e a aprendizagem. São Paulo: Ática.

YEE, D. K., \& ECCLES, J. S. (1988). Parent perceptions and attributions for children's math achievement. Sex Roles, 19, 317-333. 